\title{
El texto en representación: La escritura visual en Exit de Gonzalo Muñoz
}

The text in representation: The visual writing in Exit by Gonzalo Muñoz

\section{JuAN HerRera M.}

Universidad de Concepción. Chile

juherrera@udec.cl

\section{RESUMEN}

Este artículo aborda la escritura poética de Gonzalo Muñoz con el objeto de demostrar su vínculo con la Cultura de la Imagen. Los textos de Muñoz, tanto en su composición como en sus referencias, como también en su relación con la tradición poética chilena, expresan la crisis de una cultura impresa y el advenimiento del nuevo régimen de la imagen en el contexto de la cultura chilena de los años ochenta.

Palabras claves: Simulacro, protohipertextualidad, transmedialidad, fractalidad.

\section{ABSTRACT}

This article examines the poetic writing by Gonzalo Muñoz to show that his poetry is connected to the Image Culture. The texts by Muñoz, in regard to their composition and references therein, and the poetic Chilean tradition, represent the crisis of a print culture and the advent of a new image regime in the context of the Chilean culture of the 1980s.

Keywords: Simulacra, proto-hypertextuality, transmediality, fractality. 
T a escritura de Gonzalo Muñoz demuestra su cercanía con el régimen de lo _visual, a partir de una composición textual particular y a través de referencias relativas a esta órbita, fenómeno que es posible observar en su primer libro, Exit (1981), y que se extenderá a las siguientes producciones del poeta, Este (1983) y Estrella negra (1985). Además, esta constatación se hace extensiva y puede verificarse como una constante de los poetas chilenos de la llamada generación de los ochenta. Nuestra preocupación en esta investigación consiste en evaluar los procedimientos particulares que utiliza el autor para aproximarse a lo visual, especialmente en su primer texto; también evalúa cómo se materializan las relaciones de su escritura con la tradición poética chilena, en general, y con la producción de sus contemporáneos, en particular. La investigación es abordada desde una perspectiva crítico-teórica multidisciplinaria que sobrepasa la mirada puramente textual-verbal y se acerca al enfrentamiento del texto literario desde los estudios culturales.

\section{LA HUELLA DEL SIMULACRO-BORRADOR}

Exit es un texto de profunda experimentación en el contexto de una tradición poética chilena marcada por escrituras definidas por el lirismo poético de índole romántica, aun cuando muchos trabajos significativos, a partir de la década del cincuenta, iniciaron la transformación de esta norma (Binns, 1999; Galindo, 2005). Asimismo, el libro se relaciona con otras obras del periodo que también poseen dicho carácter experimental: La nueva novela de Juan Luis Martínez, Purgatorio de Raúl Zurita, Bobby Sands desfallece en el muro de Carmen Berenguer, por mencionar sólo algunas ${ }^{1}$. No obstante, pensamos que Muñoz es el autor, entre los citados, que logra acercarse con más decisión y claridad al complejo código del cine ${ }^{2}$. Esta relación de preferencias referenciales

\footnotetext{
${ }^{1}$ La experimentación es uno de los rasgos más destacados de las obras del periodo. Existen varios trabajos que sugieren tal situación, argumentando la existencia de un deseo de reformulación de las estéticas imperantes, explícitamente más denotativas de su contexto cultural inmediato; otros han visto razones de índole política y expresan que estos trabajos poéticos prefieren de manera consciente la amplificación del significante como una manera de complejizar el significado y así, mediante una estrategia programada, autocensurarse; alternadamente estas hipótesis coinciden en el hecho de que la poesía del periodo practica una utilización de procedimientos nacidos en las vanguardias de entreguerras (Bianchi, 1990; Alonso et al., 1989; Carrasco, 1988).

${ }^{2}$ Autores como Juan Luis Martínez y Raúl Zurita, con su producción inicial (Purgatorio y Anteparaiso), se aproximan transmedialmente a la Cultura de la Imagen mediante la mixtura de texto e imagen gráfica (fotografía, por ejemplo); Berenguer y Harris, a través de las referencias cruzadas entre historia, cine y literatura; Maquieira, articulando discursos relativos a la tradición pictórica, la escenificación de lo lírico y realizando alusiones a la música popular; Rodrigo Lira, por su parte, incrusta el código televisivo y evidencia de manera trágica el extremo de una estética de la desaparición.
} 
plantea para el autor el imperativo de realizar una revisión de los códigos y materiales pertenecientes a la representación de la imagen en movimiento. De manera específica, articula un discurso que se asemeja a aquellos producidos como borradores -bocetos- de la composición objetivamente visual, en donde la escritura constituye un diagrama de lo que será visto.

En cine y televisión, comúnmente en la fase previa al proceso de producción, es conocido el valor que poseen el storyboard, el guión literario y el guión cinematográfico, como formas de visualización del probable montaje en la fase previa a la secuencialidad definitiva de un relato-imagen ${ }^{3}$. La obra de Gonzalo Muñoz pone en práctica una simulación de tales procedimientos, la que se lleva a cabo mediante la dislocación del proceso de escritura poética, al transformarla en una tipología diferente cuando notoriamente se advierte la presencia de ciertos ruidos en el sistema que prefigura el género lírico ${ }^{4}$. Así, en el interior del propio texto se constata la presencia de una contaminación -no negativa- por medio de un discurso ajeno, de extraña naturaleza, que se materializa a través de la inserción de, al menos, un guión literario. Lo significativo de este fenómeno es que tal guión se encuentra fijado de manera absoluta, encontrándose evidencias precisas de la hibridación de un texto inicialmente poético y finito que llega a tener rasgos de visualidad. En otras palabras, se arriba a la ejecución de un texto no poético - al menos no en el sentido tradicional en la medida en que se intersectan soportes de información- ni definitivo sino provisorio, al remarcarse elementos de su carácter de borrador ${ }^{5}$. Esta advertencia prefigura toda la actividad de lectura que podamos realizar como destinatarios del texto, por cuanto también desplaza la habituación lectora frente a un poemario. Además, paralelamente, exige que ingresemos al espacio literario con cierta desconfianza o con cierta fascinación misteriosa ante la ejecución del boceto

${ }^{3}$ En la fase de preproducción se activan estas tipologías. La actualidad de la industria visual, en todas sus formas y medios, suele utilizar diversos modos de borradores, encontrándose híbridos entre los tres modos señalados. Ciertamente, las categorías indicadas en este artículo deben considerarse como modelos genéricos $y$, por cierto, no establecemos las formas discontinuas y heterogéneas con que puedan ejecutarse en la realidad particular de un trabajo audio-visual, por cuanto, en la práctica, suele ocurrir que se omitan o reemplacen por nuevos procedimientos; aquí cobran importancia las nuevas tecnologías informáticas y la derivación de estos medios hacia la telepresencia, el en vivo o la toma única.

${ }^{4} J a v i e r$ Campos (1987) es el primer crítico que anuncia escuetamente el vínculo poesía-visualidad en la obra de Muñoz.

${ }^{5}$ Además, se debe considerar que el texto se proyecta indefinidamente sin poder actualizar jamás de modo concreto su dimensión visual. La imposibilidad de consumación responderá, por otro lado, al quebrantamiento de los límites del texto escrito, a una barrera en el espacio de la representación. Otro aspecto a considerar es la similitud apreciable con la escritura de Rodrigo Lira, quien dota a sus textos de precariedad en el momento en que los posiciona como eventos proyectados de su propia muerte y de su propia vida literaria, cuando lega Proyecto de obras completas. 
señalado, lo que, en definitiva, condiciona de antemano a una lectura de alta complejidad en que el diseño de la obra resulta significativo. Esta prevalencia del significante supone una notificación de alerta para el lector, quien debe tomar medidas para no extraviarse entre los ruidos y fragmentos del texto, como en los que se presentan a continuación, donde se insertan acotaciones sobre el texto; asimismo, la distancia entre estos al interior del libro remarca su fragmentariedad:

\section{Campanillas y cencerros introducen}

a un texto ...

(sonido de micrófonos antiguos, zumbidos, pitos, voz - fotografía sobreexpuesta)... le resbalaba por la cara como agua de lluvia, por el impermeable, empapándolo, enfriándolo; esa sombra desconocida, que ni sus cigarrillos negros ni sus whiskies lograban disipar, enmascarándola al contrario de desaliento amoroso, de reflexión mística; porque quizás el verdadero rostro sólo fuera esa sucesión de escaparates sin nombres, aunque lo más probable es que ni esa forma tuviese... (Muñoz, 1981: 13).

El texto se diluye, el sonido de campanas se aleja electrizado

La galería se vacía, blanca, se silencia (Muñoz, 1981: 27).

El objeto de esta estrategia de construcción adquiere sentido cuando se comprende el deseo de elaborar secuencias discursivas dirigidas a ser eventualmente representadas en la visualidad, más que comprendidas desde la profundidad de un texto poético centrado en la subjetividad de una entidad lingüística, el yo poético. Se sugiere en estos textos una invitación a imaginar visualmente una escritura, en que la profundidad poética se materializa en los personajes representados, desplazando, mediante procesos de travestismo, la univocidad poética y la interioridad neutral, con el objeto de otorgar a la escritura un carácter objetivo. El travestismo lingüístico merece una mayor atención en la producción de subjetividades al interior de la generación en la que se inscribe la obra de Muñoz. Sin embargo, adelantamos que su carácter responde a esbozar una experiencia "trans-natural" en un texto escenificado que se deja leer desde puntos de vistas diferentes.

La vinculación entre escritura y visualidad cobra importancia en el contexto de la poética desarrollada ampliamente por los escritores chilenos de los años ochenta y, hasta cierto punto, la define, en tanto lo perseguido por estos artistas consistió en presentar la crisis de la grafósfera en virtud de la instalación completa y definitiva de la videósfera, aun cuando esta presentación anunciara 
para muchos de ellos el fin de la escritura como medio o soporte posible para el conocimiento y el arte; en definitiva, la evidencia de su escritura es motor de su propio silenciamiento escritural, muerte y fin de la creatividad, como ocurre con Juan Luis Martínez, Rodrigo Lira y Raúl Zurita, respectivamente. No obstante, es necesario indicar que el acercamiento a la dimensión de la imagen sólo es posible desde los límites de la cultura escrita. De manera más estricta, Exit no es un guión literario, opera como uno, lo simula; es decir ocurre una desterritorialización de los límites de la tipología textual poética y, a la vez, de la tipología específica visual.

El dialogismo entre la obra misma y su recepción opera como un contrapunto en el que, a discreción, es necesaria la intelección de la secuencialidad por parte del lector, pero cuya apropiación es dificultosa dado el orden fragmentario (no lineal), las combinatorias arbitrarias de segmentos y también por las reiteraciones de texto. Como consecuencia de esta exigencia de actividad significativamente participativa en la lectura, se motiva un desplazamiento del signo literario hacia una comunicación marcada por la indicialidad, en la que la información adquiere sentido en función del rol co-autorial del lector ${ }^{6}$. Por otro lado, la actitud apelativa presente en los textos en "Diálogo a dos voces" (Muñoz, 1981: 12), que podría guardar relación con un supuesto carácter teatral, tiene la finalidad de lograr una configuración intermedial de distintos órdenes discursivos que se integran sin prejuicio en el tejido de esta especie de guión literario poético, por cuanto los distintos discursos exceden por mucho la presencia de las voces de los personajes?. El texto se despliega en la medida que es posible comprenderlo como un juego (aspecto lúdico postmoderno), que no opera con un código maestro, sino con un patrón de construcción textual no lineal, fragmentario, susceptible de ser intervenido. Dicho rasgo se cruza inmediatamente con aspectos sugestivos desde el punto de vista de la crisis de la representación, dado que podemos comprender la obra en su dimensión hipertextual. No obstante, es necesario hacer un paréntesis aclaratorio al respecto, cada procedimiento articulado al interior del libro es absolutamente bidimensional, analógico e inmutable. Ningún grafo puede ser

${ }^{6}$ Debray (1995: 31) afirma que bajo el régimen del Indice, en el contexto de la videósfera, la expectación frente a los acontecimientos se transforma desde la representación a un acto en que interviene la presencia, en donde el público o la audiencia se incorpora al espectáculo.

${ }^{7}$ Otro ejemplo de diferenciación entre Exit y el género dramático queda expresado con la presencia de indicadores discursivos que se asemejan a las intervenciones del acotador (texto dramático), pero que difieren de éste en la medida que apuntan a elementos de la composición visual, para que las secuencias de imagen-texto adquieran peso contextual: "(un fondo de escenas de caza y/ pagodas en ruinas)", "(con luces sobre el fondo de la pared de negros cartones) = EXIT" (Muñoz, 1981: 14 y 15). 
alterado arbitriamente por el lector. Entonces, asumimos naturalmente que la hipertextualidad es simulada o pretendida en el texto; en resumen, se transforma en una protohipertextualidad por el trayecto expresado entre el código verbal escrito y el código audiovisual referido y partícipe de la composición (guión literario) y que el lector debe considerar para la intelección del texto ${ }^{8}$.

El borrador toma forma de simulacro en variados sentidos. Por una parte, es evidente su constante presencia en relación con los personajes (voces), los cuales se figuran y autofiguran como fantoches que deben representar una escena, una rutina escénica:

... prefería mostrarle una máscara que no fuera ni su propio gesto, y que se cubriera de velos, así y con mi cuerpo varias veces roto por adornos, cumpliría la función de acercarle un residuo, un puro objeto de manejos..."

“... arrojarme entre sus brazos diciendo a media voz algún discurso...”

galería de arte

“... allí me presentaría cubierto de flores, enfiestado, bondadoso, travestido, a mostrarle una pierna desnuda y un arco de cejas...” (Muñoz, 1981: 26).

Por otra, la simulación se activa cuando el cuadro completo se concibe como una representación artificiosa: todo el texto es una escena ${ }^{9}$. Además, esta doble presencia se plasma como relación metonímica: lo personificado se amplifica en la relación de la obra toda y la realidad contextual. Es decir, que ambas formas del simulacro se explican como transposiciones de dos órdenes al interior de la "trama" del texto, pero que deben motivar, a su vez, una relación más profunda e importante, la que guarda relación con la función metapoética del arte, porque se remarca la necesidad de problematizar sobre la representación. En otros términos, este texto, como conjunto, pone de manifiesto la vacuidad del

${ }^{8}$ No obstante, la intelección, eventualmente, puede no ser comprendida de este modo, sino que, dados los atributos del texto, ésta puede tomar la forma de una mala intelección, una lectura errada, una no interpretación de absolutamente nada o, simplemente, otra interpretación. Esto es posible dentro del contexto de la literatura postmoderna, como afirma Steven Connor en su texto Cultura postmoderna (1996: 83). Además, son precisamente los actos de desviación de la norma interpretativa los que permiten mantener en vigencia un determinado texto.

${ }^{9}$ Jean Baudrillard (1993) ha examinado ampliamente el problema del simulacro en las representaciones culturales occidentales. Nos interesa particularmente el concepto en función de su carácter artificial en el arte contemporáneo y asociado a la Cultura de la Imagen. 
acto artístico de representar la realidad, por lo menos, de una manera moderna, centrada todavía en la noción de una mimesis que persigue una forma acabada y replicante de la imagen de mundo. En este sentido dos textos sugieren al respecto la divergencia ante tales propósitos: "Prólogo" y el "Epílogo", ambos suscritos por Derrida:

\section{PRÓLOGO}

¿O bien el prólogo más allá de sí mismo es arrastrado en el movimiento que tiene lugar ante él y que no parece seguirle más que por haberle en realidad precedido?

$$
\text { J. Derrida (Muñoz, 1981: 9) }
$$

\section{EPÍLOGO}

El que escribe en el alfabeto ni siquiera imita ya; sin duda también porque imita, en cierto sentido, perfectamente.

J. Derrida (Muñoz, 1981: s/n)

Al hacer patentes los significantes involucrados, al multiplicar su presencia, la materialidad artística es devuelta como un objeto de uso (incluso común), un "resto" de la operación que materializa el texto, un "ruido" como hemos hecho notar con anterioridad, lo que queda demostrado en el siguiente fragmento:

\section{INFORME}

... se nos encontraron restos de plumas, signos trazados en la tierra con tiza, ideogramas; se encontró una acuarela de paisaje oriental; se encontró un flash de cámara de bolsillo, quemado; se encontraron tamborines, lápices de labios, manchas de sangre, cabellos, lágrimas, orina, maíz.

... se presume que todo ha sido un ritual, una orgía dirigida, una adoración sin límites, una divina presencia, una terapia grupal, un desenfreno, una invención, una puesta en escena de Dennis Oppenheim, un teatro, un instante tan solo, un mambo (Muñoz, 1981: 49).

Este acto de desenmascaramiento del propio artificio - perfil metaficcionales, a la vez, una acción descriptiva del desmontaje operado en la escritura, de mostración, y un recurso que le otorga valor al texto, dado que lo sitúa en un orden de significación superior. El simulacro de la esfera grafológica y de la esfera visual proporciona al discurso poético, en el preciso instante de su actualización, de cierto carácter (auto)irónico y paródico que debe ser 
descubierto ${ }^{10}$. La inscripción acerca del dato objetivo del guión (composiciónsimulacro) resulta paradigmática al influir considerablemente en la expectativa de un lector habituado al canon poético moderno, en donde la evidencia procedimental no tiene cabida, considerando su perfil de arte transitivo:

formato $21 \times 14$

couché blanco satinado

seminal

con seudónimo (Muñoz, 1981:39).

El anglicismo "exit" tiene como uno de sus referentes la salida del cine, la puerta de escape. Este significado se proyecta de manera simbólica al estatuto del arte moderno y de la escritura, especialmente, en el caso de la poesía.

\section{UN CIERRE-SALIDA TRANSMEDIAL}

Eugenia Brito reconoce en Exit la activación de procesos intertextuales, señalando que el texto de Muñoz se relaciona explícitamente con Cobra de Severo Sarduy (Brito, 1994: 146). Esta constatación es reveladora, según esta crítica, porque circunscribe al texto en el interior de un diálogo con la estética barroca hispanoamericana. Sin embargo, postulamos que las relaciones que el texto lleva a cabo exceden largamente las relaciones con la literatura. El tramado particular de Exit, como hasta ahora hemos indicado, permite la incrustación de variados códigos simbólicos que posicionan a la tradición literaria como uno más entre ellos. Por otro lado, Brito verifica con acierto la existencia en el texto de rasgos narrativos y dramáticos, aunque creemos que tales elementos no avalan necesariamente la hipótesis de que éstos tienen como propósito otorgar linealidad a la obra. Esto no es posible en la medida que se desterritorializan los límites genéricos que garantizan, especialmente, la progresión secuencial;

${ }^{10}$ Ricardo Piglia (2001) define que el estilo de Roberto Arlt está "hecho con restos, con desechos de la lengua" (21), una especie de trabajo con la materialidad menos prestigiosa de la lengua. Muñoz opera con residuos de distintos soportes (escrito-visual; alta y baja cultura; líricos, teatrales, narrativos); ellos se comportan como medios para notificar la fricción transgenérica y transmedial que define a parte del arte contemporáneo y la voluntad declarativa de sus autores, los cuales llaman la atención sobre la crisis de la representación en el modo moderno. En todo caso, como señalan Armand y Michèle Mattelart (2000), la restitución de estas distorsiones en la comunicación humana no configuran un escenario negativo sino uno a tener en cuenta como posibilidad al interior de los intercambios de mensajes y señalan: "para comprobar este movimiento de rehabilitación del titubeo y medir su alcance, hay que volver a situarlo, evidentemente, en un contexto más amplio que se inscribe en el meollo mismo de la crisis que altera la confianza en lo unívoco, en el meollo mismo de la crisis de los modelos racionales, de la verdad y de la norma que vertebra el logos occidental" (2000: 70). 
proponemos como causa del fenómeno la presencia de una configuración fractal.

La constatación de que la cultura visual es fractal (Mirzoeff, 2003: 49-50) es provechosa, ya que permite observar que productos de la cultura impresa vinculada con el orden visual, como la poesía de Gonzalo Muñoz, adquieren signos de fractalidad y relegan a un segundo plano el carácter lineal de la escritura. Esto condiciona la interpretación del texto según el conjunto de sus partes. Más bien, el texto, como cualquier red fractal, articula puntos de interconexión, los cuales fundamentalmente se activan por la interacción de las partes sin que esto constituya, por necesidad, una lógica determinada (causal y/o cronológica). En otras palabras, la fractalidad de Exit reside en su capacidad de articularse fragmentariamente y en la arbitrariedad en que se disponen la representación de imágenes y los procedimientos que permiten visibilizar el texto como si fuese un borrador del régimen de lo visual, pero a la vez lo remiten a la obra misma del autor.

El segundo libro de Gonzalo Muñoz, Este, se relaciona de manera restringida e intertextualmente con Exit. La primera secuencia pseudo narrativa que abre el texto, cuyo significado pareciera desprovisto de todo orden y lógica dada la difuminación de sus referentes, se colige en función de su texto anterior, Exit: "imité al viento para él / imité las arenas / imité los juncos / lo imité a él mismo" (1983: 11). Las huellas de tal procedimiento exigen una mirada atenta: “inscripción 1981" (1983: 11), "esas paredes blancas con puerta de salida afuera, de escape" (1983: 11). Frederic Jameson (1999) afirma que el arte contemporáneo y otras expresiones culturales que operan con la representatividad tienen como atributo una naturaleza relacional con obras precedentes: el pastiche (1999: 18 y ss.). La imitación de un objeto cultural verifica una constante postmoderna: la creatividad y la poesis se encuentran confinadas a la exhibición de las combinatorias de lo ya establecido, lo que finalmente define su existencia como producción artística. Por ello, la rearticulación de contenidos de acuerdo a estrategias paródicas -en su sentido deferente, "al lado de" (Hutcheon, 1981)-, de pastiche, montaje, collage y otras técnicas, cobran sentido, justificando así la pérdida o distanciamiento de una pretendida originalidad del discurso artístico $y$ en donde el mundo representado apunta invariablemente a otra obra ${ }^{11}$. La evidencia de tales procedimientos es notable en la primera parte de Este y apuntan directamente a Exit como precuela del segundo libro del autor.

\footnotetext{
${ }^{11}$ En la poesía chilena de la década de los ochenta e incluso un poco antes es posible rastrear la materialización del inter-estilo, así Purgatorio de Raúl Zurita (1979) retoma procedimientos de La nueva novela de Juan Luis Martínez (1985), como Tomás Harris $(1996,1997)$ hace lo propio con los discursos coloniales y de conquista.
} 
Una vez situada la escritura primaria de Este, su urtexte, toma lugar el traslado de este carácter vincular del texto hacia el orden de la representación. Es decir, se fija la relación en el propio texto y, además, se efectúa una reflexión al respecto. El concepto de escritura entonces adquiere relevancia como problema, como temática de Este y, en verdad, resulta una constante de la poética de Muñoz, como ha quedado demostrado en la alusión a Derrida. La escritura occidental tiene progresión sintagmática de izquierda a derecha, simbólicamente, de Oeste a Este, pero aquí la escritura realiza un salto hacia atrás, al pasado:

(...) la línea que siempre me devuelve al instante an-

terior. De nuevo. hasta comenzar a caer sin apo-

yo retratado a intervalos, perdida la visión: esas

paredes blancas con salida afuera, de

escape (...) (Muñoz, 1983: 11).

En consecuencia, se expresa, por una parte, una reflexión acerca de la escritura como soporte, pero, por otra, la referencia es explícita a la portada del libro Exit, señalando características de la portada, como la fotografía de Soledad Fariña V. El carácter hermético del texto se abre en la medida que es posible leerlo en relación directa con su doble anterior en relación fractal, "QUIEN SINO, ME VA A LEER DE ADELANTE/ATRÁS" (Muñoz, 1983: 23). Además, al establecer una especie de lógica dialéctica, otras duplicidades entran en juego: horizontales-verticales; arriba-abajo; sí-no; Este-Oeste; abiertocerrado; rechazo-atracción. Polaridades que expresan la necesidad de la esencia doble, de la existencia en función de un anverso, un otro, una dimensión especular. Muñoz lleva a cabo una escritura fragmentariamente progresiva que se despliega sobre el cierre que metafóricamente expresa la palabra "exit" en el espacio que reconocemos como sala de cine, que es donde "ocurre" el texto; no obstante, simbólicamente, amplifica esta noción hacia parámetros más complejos, los cuales refieren a la caducidad de la representación de la obra de arte en términos cerrados; por ejemplo, como bien apuntara Brito, se extienden al código pictórico (Brito, 1994: 149). Explícitamente, el "cierre" implica, además, una "salida" complementaria y nodal desde el punto de vista fractal que incorpora transmedialmente una forma nueva de soporte, la pintura, que gráficamente adopta una estructura en "La doble grabación".

La obra se revisita, porque su germen visual determina que las imágenes permanezcan en latencia y les confiere su capacidad de ser re-presentadas como si el borrador descrito tomara forma, como si estuviese ocurriendo su representación. De este modo, los "restos", los residuos, los "despojos abandonados", irrumpen como intensidades residuales con las cuales trabajar 
("todo es material de trabajo" (Muñoz, 1983: 18)) y son, al mismo tiempo, memorias restituidas nuevamente al proceso de escritura que, por efecto de su recursividad, adquieren sentido. Este mecanismo se instala como una forma de expiación común a la actividad artística del país durante el periodo que nos ocupa, según señala Nelly Richard:

La Avanzada trabajó con el resto, con los desechos de la representación. Se propuso estilizar los cortes y las fracturas de una temporalidad violenta mediante la sintaxis de lo disociado y lo inconexo, de lo no integrable. Estos fueron los modos en que el arte y las escrituras de la Avanzada trabajaron con las fallas y los accidentes de la representación, perforando y escindiendo la linealidad de una historia y una memoria que se pretendieran indemnes (Richard, 2004: 32).

El ejercicio de la memoria es también una alerta del accidente. La escritura es recuerdo de una escritura previa accidentada y testimonio de un desastre social. Por ello nos parece significativo que en Este la subjetividad hablante se enfatice en mayor medida que en el caso del texto anterior, ya que actúa como medio de la memoria de las otras subjetividades (actrices, travestidos, etc.). Sin llegar a ser testimonial, en el sentido estricto del género, Este articula una serie de formulaciones alusivas a la muerte, expoliación y tortura, que permiten notificar al lector su relación con el contexto. La carnavalización que en Exit puede confrontarse, en el segundo libro de Muñoz cambia su sentido, adquiere matices trágicos. De hecho, la inserción de la serie "E(x)it" en Este, se encuentra absolutamente teñida por esta figuración, como puede observarse en el texto siguiente, en el que, a través de un juego tipográfico altamente logrado, se demuestra la irrupción de la negatividad, pero también el enlace de fractalidad:

10. EX.
sumamos entonces a la lectura anterior
un nuevo eco, doblado, que recuerda
a la tumba de sus desvelos/
una lámina volteada sobre las pasadas
manteniendo al cuerpo sellado en sus interior,
series son el resto de inviernos mudos

las paredes

superpuestas

del lecho blanco

sepultura 
Ex -citación del cuerpo en su papel de muerto recorrido del pozo sin fondo

\section{PUES NO FUE UN CRIMEN PERFECTO EL QUE NOS COMETIERON}

NI EN LA ORILLA

(Muñoz, 1983: 63).

Probablemente, la entrada en la salida sea un acto de máxima resistencia en el discurso de Muñoz, tanto desde el punto de vista estético, con todas las operaciones descritas, como desde la contingencia sociocultural chilena, y con esto recuerde los proyectos poéticos de los años ochenta de Carmen Berenguer (Bobby Sands desfallece en el muro y Huellas de siglo), Elvira Hernández (La bandera de Chile) y Eugenia Brito (Via pública), quienes sostuvieron en sus escritos un similar modo de relación. Sin embargo, existe una diferencia radical, desde nuestro punto de vista, con la mayoría de las demás voces que pusieron en evidencia el desastroso estado de la civilidad chilena; Muñoz no condicionó su resistencia a un modo único, que incluso podríamos considerar redundante. Por el contrario, al tiempo que mostraba el derrumbe de las posibilidades de la representación en la escritura, asociaba esta idea a la de un quebrantamiento social como dimensión extratextual.

Esto nos permite realizar una breve digresión, a fin de dejar en claro el cuidado que hemos puesto en no caer rendidos ante la exclusiva lectura políticoideológica que se suele realizar sobre los productos culturales de los años ochenta, ni tampoco pensarlos desasidos de su contexto: hemos sido testigos, muy a menudo, de la manipulación que se ejerce sobre el patrimonio poético; también hemos visto cómo tal situación degenera en la hipertrofia del excedente de memoria que, como observara Andreas Huyssen (2000), no habilita la posibilidad de producir el futuro. Muñoz intervino su realidad críticamente, este ejercicio se configuró al interior de una cultura grafoesférica en crisis, que daba paso a una centrada en la imagen, cuestión que no debemos perder de vista, dadas sus amplias repercusiones, si queremos hoy construir nuestro futuro cultural.

\section{REFERENCIAS}

Alonso, María Nieves; Mestre, Juan Carlos; Rodríguez, Mario y Triviños, Gilberto. 1989. Las plumas del colibrí. Quince años de poesía en Concepción (1973-1988). Santiago: Improde/Cesoc.

Baudrillard, Jean. 1993. Cultura y simulacro. Barcelona: Kairós.

Berenguer, Carmen. 2002. La gran hablada. Santiago: Cuarto Propio. 
Bianchi, Soledad. 1990. "Una suma necesaria (Literatura chilena y cambio: 19731990)", en Revista Chilena de Literatura 36, pp. 49-62.

Binns, Niall. 1999. Un vals en un montón de escombros. Poesía hispanoamericana entre la modernidad y la postmodernidad (Nicanor Parra, Enrique Lihn). Bern: Editorial Científica Europea.

Brito, Eugenia. 1984. Via pública. Santiago: Editorial Universitaria.

_. 1994. Campos minados. Literatura post-golpe en Chile. Santiago: Editorial Cuarto Propio.

Campos, Javier. 1987. “Tomás Harris y la cultura de la imagen. Algunas reflexiones sobre la poesía chilena de los 80", en Revista Chilena de Literatura 40, pp. 8790.

Carrasco, Iván. 1988. "Antipoesía y neovanguardia”, en Estudios Filológicos 23, pp. $35-53$.

Connor, Steven. 1996. Cultura postmoderna. Introducción a las teorías de la contemporaneidad. Madrid: Ediciones Akal.

Debray, Régis. 1995. El estado seductor. Las revoluciones mediológicas del poder. Buenos Aires: Manantial.

Galindo, Oscar. 2005. "Neomanierismo, minimalismo y neobarroco en la poesía chilena contemporánea", en Estudios Filológicos 40, pp. 79-94.

Harris, Tomás. 1996. Cipango. Santiago: Fondo de Cultura Económica. .1997. Crónicas maravillosas. Santiago: Editorial de la Universidad de Santiago de Chile.

Hernández, Elvira. 1991. La bandera de Chile. Buenos Aires: Libros de Tierra Firme.

Hutcheon, Linda. 1981. "Ironie, satire, parodie, une approche pragmatique de l'ironie", en Poétique 46, pp. 141-155.

Huyssen, Andreas. 2000. "En busca del tiempo futuro". [En línea]. Disponible en http://www.cholonautas.edu.pe/modulo/upload/Huyssen.pdf [Consulta: $14 / 04 / 2009]$.

Jameson, Frederic. 1999. El giro cultural. Buenos Aires: Manantial.

Lira, Rodrigo. 2003. Proyecto de obras completas. Santiago: Editorial Universitaria.

Maquieira, Diego. 2003. La tirana/Los sea Harrier. Santiago: Tajamar Editores.

Martínez, Juan Luis.1985. La nueva novela. Santiago: Ediciones Archivo.

Mattelart, Armand y Mattelart, Michèle. 2000. Pensar sobre los medios. Comunicación $y$ critica social. Santiago: Lom.

Mirzoeff, Nicholas. 2003. Una introducción a la cultura visual. Barcelona: Paidós.

Muñoz, Gonzalo. 1981. Exit. Santiago de Chile: Ediciones Archivo. 1983. Este. Santiago de Chile: Talleres Editorial Universitaria. 1985. Estrella negra. Santiago: Francisco Zegers Editor.

Piglia, Ricardo. 2001. Crítica y ficción. Barcelona: Anagrama.

Richard, Nelly. 2004. "Lo político y lo crítico en el arte", en Revista de Crítica Cultural 28, pp. 30-39.

Zurita, Raúl. 1979. Purgatorio. Santiago: Editorial Universitaria. 1997 [1982]. Anteparaíso. Santiago: Editorial Universitaria. 